\title{
Effects of Change Management on the Performance of Firms in Nigeria
}

\author{
Dr. Cross Ogohi Daniel \\ Department Of Public Administration/Banking and finance \\ Nile University Of Nigeria \\ Abuja, Nigeria
}

\begin{abstract}
This paper is on the effects of change management on the performance of firms in Nigeria. The paper sought to determine the effects of organization enabler on growth and assess the nature of the relationship between management change and organizational effectiveness. The sources of data for the study were primary and secondary. Change Management is also used to define the process of following the change in the automated system, logging best practices or system upgrades. Management of change connects to people's encounter and the organizational process. The secondary source of data generation, which comprises of the use of textbooks written by different authors on the subject matter, journals, magazines, information from the internet and other published and unpublished materials applicable to the work. The study concludes that change is inevitable and managers all over the world are adapting to changing market conditions and at the same time facing the need for creating a proactive rather than a reactive managerial system.
\end{abstract}

Keywords: Change Management, Performance, Organizational Enabler, Organizational growth.

\section{INTRODUCTION}

Change is unavoidable and managers all over the world are adjusting to the changing market conditions and at the same time facing the need for generating a proactive rather than a responsive managerial system. They are examining for ways to cope with an increasingly complex technology and more refined labor force or teams. To achieve varied goals, managers need more than fragmentary ad-hoc change programmes dealing only with present challenges.

They need change management methods to prepare for upcoming organizational competitive difficulties. Managers must gain knowledge how to build and manage a human group that is proficient of foreseeing the new, capable of changing its vision into technology, products, processes and services, willing and able to agree with the new. Attempts to execute change management have been many and extensive, but the promises made in its name have remained unsatisfied [1].

Influential forces in the environment such as technology, competitors, and regulators amongst others are unceasingly influencing public and private organizations to change permanently present structures, policies, and practices. A major element of change is the application of policies. Implementation is therefore a key concern in the management of change [2]. The inability to get things done and have crucial ideas and decisions implemented is widespread in organizations today [3].

Osisioma (2004) argues that change is the single most important element of successful business management today and as such, it is a fact of life that organization managers should anticipate change in order to remain competitive in increasingly aggressive markets and adopt a positive attitude to it since this is inevitable in the history of any organization. Ignoring or trivializing a changing trend can be costly, thus managing change teaches managers how to be ahead of rivals and it ensures the long-term survival of the organizations.

McShane and Glinow (2004) Maintains that strategic change implies visionary or transformational change, which is concerned with broad long term and organization wide issues. It focuses on moving the organization to a future desired state and also covers the purpose and mission of the organization. It makes a noticeable impact on the organization, or on the part of the organization undergoing the change.

Ezekiel (2004), there are two types of forces involved in managing change process generally and these include "the driving forces that set in motion the change process and the restraining forces that resist the change process in organizations". This clearly reveals that one of the major problems confronting managers in managing any type of change is resistance to change.

Udeh and Igwe (2013) states that while change can cause confusion and fear, there are several positive effects it can have on organizational performance if handle properly. Understanding the positive effects of change helps to better gauge progress in developing change management policies within the organisation. The organization may use change management when 
implementing policy changes to the management of the organization, production methods or employee policies. The systematic approach to making changes in the organization attempts to transit employees through the disruption a change can cause. While the system attempts to minimize the negative effects, employees and management can have trouble with the change.

Westenholz (2013) state that change remains a necessity despite the several difficulties and challenges faced by the Nigerian Firms. It is the only way for organizations to consistently adapt to new trends, react to competitors and meet the needs of their customers. The challenge facing Nigerian firms therefore is not to avoid change and attain a state of changelessness. It is to manage change, that is seek change, initiate it, keep looking for something new to add, something old to discard and do all these with minimum undesirable effects as possible. Nigerian firms are facing unprecedented levels of change and as a result the need to manage change and deuce its effects successfully should be a core organizational competence.

\section{LITERATURE REVIEW}

\subsection{Concept of Change Management}

Change management has typically been defined as a process involving unfreezing, moving, and refreezing values, practices, and procedures within organizations. Unfreezing refers to the creation of a perceived discrepancy between the existing and ideal state of an organization that generates a desire for change and lowers people's resistance to change. Moving refers to the various processes such as training, education, and restructuring that lead to the development of new behaviours, attitudes, and beliefs. Refreezing regards "reestablishing a new state of equilibrium within the organization by stabilizing the new patterns through a variety of support mechanisms" [9].

Change is often refused by organizational members. The primary reason for refusal is that change necessitates employees to adjust their existing individual and organizational identities. Changing one's identity can be anxiety infuriating and it is common for employees to use tactics such as denial, rationalization, idealization, fantasy, and symbolization to resist change [10]. Change Management is also used to define the process of following change in automated system, logging best practices or system upgrades. Management of change connects to people's encounter and the organizational process. Change management is 'the coordination of a structured period of transition from situation ' $\mathrm{A}$ ' to situation ' $\mathrm{B}$ ' in order to achieve lasting change within an organization' [11]. Management of change is the systemic approach and application of knowledge, tools and resources to deal with change. Management of change means "defining and adopting corporate strategies, structures, procedures and technologies to deal with changes in external conditions and the business environment" [11].

Change management is a "systematic approach to dealing with change, both from the perspective of an organization and on the individual level". Change management is an organized approach to changing individuals, teams and organizations from a present state to a desired future state, to achieve or implement a vision and policy. It is an organizational process intended at empowering employees to admit and embrace changes in their present environment. There are different streams of thought that have formed the practice of change management [12].

Change management is the official process for organizational change, comprising of a systematic approach and application of knowledge. Change management means "defining and adopting corporate strategies, structures, procedures, and technologies to deal with change stemming from internal and external conditions". Management of change is a critical part of any plan that leads, manages, and allows people to accept new processes, technologies, systems, structures, and values. It is the set of actions that helps people transform from their present way of working to the desired way of working. Change management is "the continuous process of aligning an organization with its marketplace-and doing so more responsively and effectively than competitors" [13].

\subsection{Effects of Managing Change in Organizations}

Organizations are conglomerates of dynamic systems that constantly change. The organizational boundaries as well as the boundaries of their internal systems are permeable. Organizations are also complex in several different ways: environmental (variations in the environment outside of the organization), component (number of organizational components and their relations), and hierarchical (number of levels and their relations). Although we can't eliminate complexity, we can manage it. We can manage environmental complexity by aligning the internal systems to the environmental demands.

Marh (2001) suggests that where change is intended in an organisation, the effect is that there will be forces acting to facilitate the change, and forces acting to resist the change. A state of equilibrium occurs, which is brought under pressure to change by both internal and external driving forces. When the balance of the forces for and against change is equal, no change will occur. In order to implement change, those forces supporting change have to be strengthened, those resisting change weakened, or both.

Udeh and Igwe (2013) states that while change can cause confusion and fear; there are several positive effects it can have on organizational performance. If handle properly. Understanding the positive effects of change helps to better gauge progress in developing change management policies within the organisation. The organization may use change management when implementing policy changes to the management of the organization, production methods or employee policies. The systematic approach to making changes in the organization attempts to transit the employees through the disruption a change can cause. While the system attempts to minimize the negative effects, employees and management can have trouble with the change. 
The positive effects of managing change include:

1. Employee Confidence: When organization successfully complete a significant change and the employees see that none of the fears they held regarding change are realized, such organisation are paving the way for smoother change in the future. One of the positive effects of efficient change management is that it instills confidence in employees regarding the management's ability to lead the organisation and make good business decisions. This not only makes future changes easier, but employee confidence also makes day to day decision-making simpler as well [7].

2. Competitive Advantage: The ability for the organization to change helps maintain competitive advantage in the marketplace. For example, if your competition has implemented a new order-entry system that makes the process of doing business easier on the customers, then your ability to adapt to that change and institute your own order-entry changes helps keep you competitive. The ability to institute change quicker and more efficiently than the competitors gives you an advantage that can help you achieve, or maintain, the status of an industry leader [7].

3. Growth: Organisation must experience change to experience growth. Organization can continue to do things the same way for a long period of time. But, at some point, organization's infrastructure needs to change to accommodate a growing customer base and industry changes. New processes, new marketing concepts and improved ways of reaching the target market all require changes within the organisation. Your company's ability to facilitate change enables it to grow [7].

4. Dynamic: A corporate culture that embraces change is one that tends to remain dynamic in the marketplace. Because employees are confident that the organization can manage change, new ideas flow more freely. Employees do not feel bound by the current organizational structure because they know the organisation can adapt to meet the challenges of the future. A dynamic atmosphere with an openness to change is a productive and forward-thinking workplace [15].

The negative effects of managing change include:

a. Employee Resistance: Implementing a new policy can result in employee resistance. Employees resist change when there is not a clear understanding of the reason for the change. A lack of knowledge on how it will affect their work can also cause employees to resist. Workers with personalities that require process and reliability in their work life will find change a difficult adjustment [16]

b. Expense: Handling a change in the organisation effectively can take time, which can result in cost of production and expense. The change process requires training and communication to employees affected by the change. For example, implementing a new continuous improvement system in an organisation requires training for all employees in the tools, methods and processes the new system needs for success [17].

c. Lack of Support and Failure: A lack of support for change management can cause new policies and processes to fail. Employees and management must be on board with the change process for success. The system will fail if employees do not use the new system or policy and management does not enforce the change. Before a company begins the change process, it is vital that management and employees support the decision and make a commitment to the new policy or process [17].

d. Low Employee Morale: If the company does not handle change effectively, it can have a detrimental effect on the morale of workers. Low employee morale has a negative effect on productivity, which can cause a financial loss for the organization. Lowered employee morale also results in increased absenteeism and high employee turnover [15].

\subsection{Essential Enablers for Organizational Growth}

Nadler (1990) States that organization enabler involves strategy and leadership, corporate culture, people and information technology. It is the tools and resources, and the culture of the organization that will enable it, to achieve strategy. The base essential enablers for organizational growth include the following:

\section{Having a Clear Vision}

This might seem obvious to some but it is not an uncommon thing for organizations to get so busy with the day-to-day that they lose sight of who they are and what it is they are trying to accomplish. Having a well written vision statement that is displayed throughout the organization is one way to help keep that focus [17].

\section{Having a Strategy to Achieve the Vision}

Planning is one of those exercises that people either love or hate to do. But a well thought out and written strategic plan is imperative for organizations who are trying to move forward. Strategic planning processes are intended to stop the organization for a time and really think through where they are and where it is they are trying to go. It also helps keep the organization from veering off into areas that may not line up with the vision [16]. 


\section{Staying Current with Changing Trends and Technology}

Business trends and technology are changing so quickly those organizations that don't make it a business priority to learn current trends will soon find themselves at a disadvantage. This can be overwhelming, and somewhat of a whirlwind, but creating a process to learn and stay current is critical to long term success [16].

\section{Having Goals}

Writing and implementing business goals is the practical side to achieving vision through strategy. Mapping out a plan on how to take the steps to get to where the organization wants to go is critical to goal attainment. Taking those goals down to the employee level is the next step of the process. Employee goals should be standard for all levels of the organization so employees can see how what they do affects achieving the organization's vision. [15].

\section{Understanding Who Their Customers Are and What They Want}

It is amazing the number of organizations out there who are in business and don't have a good grasp on who their customers are and what their customers want from them. All organizations should have a process in place to gain customer perspective from customer comment cards or customer satisfaction surveys, and to take that feedback and turn it into improvement plans [13].

\section{Taking Care of Their Employees}

Employees are the ones who do the work and interact with the customers. Organizations need to take care of their employees and give them the necessary resources to do their job. Assessing the environment from the employee's perspective through employee satisfaction surveys and incorporating employee feedback into planning is another critical step organizations should take [7].

\section{Having a Good Performance Management Process}

Successful organizations have learned the value and importance of good performance management. Employees need to have a good understanding of what is expected of them and how they are accountable for those expectations. Good communication and coaching can help with developmental opportunities for employees and may also identify those employees who may not be the right fit for the organization. Structured communication processes are important and can minimize post-employment litigation if done appropriately [7].

\section{Managing Resources}

Budgeting and managing business resources are critical to the long-term health of an organization. Taking risks and leveraging assets can quickly turn to disaster as we've seen over the last couple of years. Having a consistent budgeting process that lines up with corporate objectives that is managed appropriately is critical. Keeping a watchful eye for employee fraud and data theft is also important in overall business asset management [8].

\subsection{Approaches and Tools of Change Management in Organizations}

Much of the change management literature continues to reflect a mechanistic view of organization and management, with an expectation of relatively straightforward cause and effect relationships between the factors that stimulate change, the change initiatives or interventions undertaken in response to those stimuli, and outcomes that will result from those initiatives. Recently, particularly in discussion about the challenges posed by disruptive changes in technology and the external environment and organizations that diverge from the dominant hierarchical bureaucratic form, there is growing debate about the ability of logical, empirical analysis to provide the insight and creative response needed for successful transition or transformation.

Critics have suggested that the change management literature has been subject to fads and hyperbole, reaching "evangelical proportions" of advocacy for change management strategies such as business process re-engineering and total quality management while failing to incorporate sound principles of organizational design [10].

Reflecting the sustained interest in organizational change and change management, a wide variety of tools have been developed to both initiate and manage organizational change and to control and direct change caused by unplanned disruptions. Many of the most popular tools are focused on achieving quality improvements addressing worker concerns; and enhancing flexibility by changing organizational structure, processes, people, and/or culture. The choice of approach or tool depends upon the organization's nature, resources and problems must be tailored to the specific contest and organisation [11].

Andrews (2008) states the following as approaches and tools for organizational change and improvement that are used in change management:

1. Backward Mapping: Start with the end in mind, working backward from the desired end state to identify pathways to success.

2. Balanced Scorecard: Ensure well-rounded performance, especially from managers, by designing an evaluation that takes into account the perspective of clients/customers, manager, peer, and subordinate on four dimensions: customer service, internal business processes, learning and growth, and financials 
3. Benchmarking: Use standards or measures from high performing organizations as basis for comparison - results from benchmarking need to be used as part of an overall change process; just doing the benchmarking doesn't lead to change.

4. Business Process Re-engineering: Increase performance by radically redesigning the organization's structures and processes, including starting over from the ground on up.

5. Continuous Improvement: Improve performance and customer satisfaction through continuous and incremental improvements to processes, including removing unnecessary activities and variations - represented as a quality initiative.

6. Cultural Change: Accomplish radical and fundamental change by changing the basic values, norms, beliefs, etc among members of the organization.

7. Employee Involvement: Engaging personnel from throughout the organization to identify issues, propose solutions, and become partners in implementing the changes needed to succeed in present and future environments.

8. ISO9000: Implement internationally recognized standards of performance and quality using guidelines especially focused on environmental performance.

9. Knowledge Management: Collect and manage critical knowledge in an organisation to increase its capacity for achieving results, often involving extensive use of computer technology - impact depends on how well the enhanced, critical knowledge is applied to the organisation.

10. Learning Organisation: Exchange organizational systems (including people) to increase capacity for performance impact depend upon how well the enhanced ability is applied in the organisation.

11. Management by Objectives: Align goals and subordinate objectives throughout the organisation - a form of planning.

12. Organizational Design: Redesign the organisation to address inadequacies and build new, more appropriate capabilities and processes, including organizational self-design and learning.

13. Outcome-Based Evaluation: Assess impact of services and products on target communities, identify outcomes necessary to accomplish objectives with target market, construct measures for each outcome to assess extent of achievement.

14. Total Quality Management: Ensure that the organisation consistently meets or exceeds customer requirements and continually improves by measuring processes and imposing controls.

\section{STATEMENT OF THE PROBLEM}

There are issues with haphazard change management techniques in these organizations. The top echelons of the firms are suspected of serving only their interest by manipulating relevant change management data. The implications of the above scenario pose a tremendous threat to both the firms and the nation. To the firms they will not be able to improve productivity and create needed jobs. On the side of the government, the revenue accruable to the government by non-performing firms would be missed greatly. Thus, the government's much trumpeted vision of the country joining the league of 20 most industrialized economies come 2020 is gradually turning into a slogan like many others before it such as Housing for All, Water for All, etc. Thus, the study focuses on effects of change management on the performance of firms in Nigeria.

\section{OBJECTIVES OF THE STUDY}

The broad objective of the study is to assess the effects of change management on the performance of firms in Nigeria. The following are the specific objectives for the study:

(i) To determine the effect of organization enabler on growth of the Nigerian firms.

(ii) To assess the nature of the relationship between change management and organizational effectiveness.

\section{RESEARCH METHOD}

The paper adopted a singular source of data collection. The secondary source of data generation, which comprises of the use of textbooks written by different authors on the subject matter, journals, magazines, information from the internet and other published and unpublished materials applicable to the work. The data was examined using the content analysis approach. This is because of its major dependence on the secondary source data.

\section{CONCLUSION}

The study concludes that change is inevitable and managers all over the world are adapting to changing market conditions and at the same time facing the need for creating a proactive rather than a reactive managerial system.

Ignoring or trivializing a changing trend can be costly, thus change management teaches managers how to be ahead of rivals and it ensures the long term survival of the firms. Failed projects can result in huge financial losses for an organization, but a failed strategic initiative has an impact far beyond just the finances. Successful organizational change management requires a commitment to transform from what an organization is into what it wants to be.

All firms go through change. Some firm's productivity opts to change to take advantage of new growth and opportunities; other firms are forced to quickly change to survive and remain competitive for better performance. Performance symbolized by growth 
rate of revenue, financial strength return on equity, return on assets and profitability. Organisations with engaged employees have customers who use their products more, and increased customer usage leads to higher levels of customer satisfaction.

\section{RECOMMENDATIONS}

Based on the findings of this study, the following recommendations were made:

1. Since change is a fact of life, managers in the Nigerian firms should anticipate effective process of managing change and organization enablers such as culture, structure people and it infrastructure need to be considered for improvements if organizational performance is to be achieved.

2. As much as it is possible, sufficient resources should be allocated (that is, financial, personnel, technical support) to ensure, successful strategic change management in Nigerian firms.

3. Nigerian firms should recognize the critical importance of compensation and benefits since these represent significant costs for the organization and should therefore be carefully monitored and controlled.

4. Nigerian government at all levels should continue to create conducive environment for implementation of change in organizations.

\section{REFERENCES}

[1] Dawson, P. (2013) Reshaping Change in Processional Perspectives. London: Routledge publisher.

[2] Pfeffer, J. (1992) Managing with Power; Politics and Influence in Organizations. Boston, Mass: Harvard Business School Press.

[3] Arora, K. C. (2009) Total Quality Management. ( $3^{\text {rd }}$ Edition); New Delhi: Kataria, S.K. and Sons Publishers.

[4] Osisioma, B. C. (2004) "Management of Change; An Overview of the Nigerian Corporate Profile", Management in Nigerian 40(2-4) April-Dec.

[5] Mcshane, S. I. and Glinow, M. V. (2004) Organisation Behaviour. ( $1^{\text {st }}$ Edition); New York: McGraw-Hill Publishing Company.

[6] Ezekiel, O. (2007) “Change Management in Process Change, Information Systems Control Journal, 20(3) July-August.

[7] Udeh, S. N. and Igwe, N. N. (2013) "Effects of Mergers and Acquisitions on Return on Capital Employed and Dividend per Share Indices of Companies in Nigeria. International Journal of Business Administration, 4(5), pp51-72.

[8] Westenholz, A. (2013) "Main Aspects Regarding the Implication of Change

Management in an Organisation", Research in the Sociology of Organizations, 27(1).

[9] Nickolas, F. (2010) Change Management: A Primer (pdf document: 526.24KB).

[10] Andrews, J. (2008) “All Change? Managers' Experience of Organizational Change in Theory and Practice”, Journal of Organizational Change Management,21(3).Annual Review of Psychology, Vol. 50

[11] Bond, C. (2008) Outcome Realization and Organizational Change Management-the Tasmania Government Approach, Department of Premier and Cabinet, Tasmania.

[12] Lewin, K. (1951) Field Theory in Social Science: Selected Theoretical Papers by Kurt Lewin, Ed. Dorwin Cartwright, Boston, Massachusetts: MIT Research Center for Group Dynamics and New York: Harper and Brothers publishers.

[13] Child, J. (2005) Organization; Contemporary Principles and Practice, Malden MA: Blackwell Publishing

[14] Marh (2001) “Today Markets Audits and Research Service”, Business Day, August 12, p. 17.

[15] Marshak, R. J. (2004) "Morphing: The leading edge of organizational change in the

[16] McNamara, C. (1999) Basic Context for Organizational Change. Available URL: http://www.mapnp.org/library/mgmnt/orgchnge.htm. retrieved on 10th January, 2015.

[17] Nadler, D. A. (1990) Concepts for the Management of Organizational Change, in Mabey, C. and Mayon-White, B. (eds), Managing Change. ( $2^{\text {nd }}$ Edition); London: Paul Chapman/Open University Publishers. 